\title{
Texto, memória e fala: um encontro com François Khan
}

\section{Text, memory and speech: a meeting with François Khan}

Fernando Manoel Aleixo ${ }^{1}$ 
Resumo

Neste artigo apresento uma reflexão sobre a memorização do texto no trabalho do ator, considerando o ato de escrever como procedimento para a assimilação do sentido da palavra, à luz da experiência realizada na oficina "A caminho do Jardim das Cerejeiras", sob a coordenação de François Khan. São descritos alguns procedimentos, seguidos de análise e conceituação sobre o processo de apropriação do texto e a composição da fala.

Palavras-chaves: Voz; memória; fala poética.

\section{Abstract}

This article presents a reflection on the memorization of the text in the actor's work, considering the act of writing as a procedure for the assimilation of the meaning of the word, under the light of an experience acquired in the workshop "A caminho do Jardim das Cerejeiras", coordinated by François Khan. Some procedures are described and followed by analysis and conceptualization of the process of text appropriation and the composition of speech.

Keywords: Voice; memory; poetic speech.

ISSN: 1414.5731

E-ISSN: 2358.6958

1 Prof. Dr. Programa de Pós Graduação - Mestrado em Artes. Universidade Federal de Uberlândia (UFU). Uberlândia, MG, Brasil. aleixo@demac.ufu.br 
O texto escrito. A Palavra - É certo que o texto enquanto atuação lógica permanece em contradição com a realidade. Na vida, de fato, não falamos nunca de maneira lógica. Aparece sempre uma espécie de lógica paradoxal entre aquilo que dizemos e aquilo que fazemos. E, mesmo assim, se vivemos plenamente, as palavras nascem das reações do corpo. Das reações do corpo nascem a voz, da voz, a palavra. Se o corpo se torna um fluxo de impulsos vivos, não é um problema impor-lhe uma certa ordem das frases. Uma vez que é como se os impulsos engolissem aquelas frases, sem mudá-las as absorvessem. Em tal caso, a interpretação do texto não constitui absolutamente um problema: aquilo que acontece de vocês, o interpreta por si só. Se a palavra é necessária e o homem que age não tem aqueles impulsos vivos, porque se exercitou só nos movimentos, o instante em que deverá falar será um momento de grande resistência, porque nisso a sua vida é ilusória. Porque trata o próprio corpo como o mímico, ou com a consciência que move a marionete do corpo. A palavra não pode ser absorvida por algo do gênero e nem pode nascer de uma tal atitude (Grotowski, 2007, p. 2004).

Na edição de número 06 desta mesma revista Urdimento, publicada no ano de 2004, que abordou o tema "teatro e memória" tive a oportunidade de publicar um artigo intitulado: "A voz (do) corpo: memória e sensibilidade. Naquela ocasião, as pesquisas sobre a voz evidenciavam os estudos práticos sobre o corpo, a presença e a memória no trabalho da vocalidade poética do ator:

A presença corpórea do ator por meio do movimento, da voz e da ação é a materialidade da cena que cria e instaura relações intercorpóreas e sinestésicas. [...] Nesta dimensão - concreta e sensorial - a voz do ator existe na sabedoria do corpo. É o corpo que sabe o caminho da produção vocal, do movimento e da sua expressão. Trabalhar a voz do ator é investir no desenvolvimento de um saber concreto detido por nossa carne, pois a voz é uma manifestação corpórea e deve ser aperfeiçoada por meio de elementos que objetivem um processo de aprendizado sensível. Neste sentido, estabelecer condições corporais favoráveis à manifestação plena da voz é, para o ator, mergulhar em um território pessoal e reconhecer o potencial que representa seu material sensível (Aleixo, 2004, p.149).

Nesta evidência da corporeidade, considerava que "o aspecto da memória, como componente da experiência do corpo permite o desenvolvimento das possibilidades vocais, integrando percepção e inventividade" (Aleixo, 2004, p.149). É justamente sobre a perspectiva da percepção e da inventividade que quero aqui retomar a questão da memória no trabalho vocal. Mais precisamente, vou abordar a questão da memorização do texto enquanto percepção sensível dos sentidos das palavras, considerando o momento em que o ator está diante da apropriação do material textual para a composição da fala que se pretende poética: sua força de inventividade. Este recorte, portanto, demanda distinguir a memória como sendo as experiências acumuladas no corpo e a memória que possibilita reter o texto a ser falado. As próprias modalidades destas "distinções" de memórias são apenas livres apropriações para conduzir uma reflexão, isto é, não pretende-se aqui debruçar sobre a definição e o conceito de memória. Em relação a isso, o processo de memorizar o texto constitui a incorporação dos sentidos que este texto gera para o ator. Essa incorporação pelo sentido das palavras, ou melhor, pelos sentidos que emergem a cada encontro com as palavras é, sem dúvida, a evidência que constitui a essência do trabalho de memorização do texto.

Farei, contudo, uma reflexão sobre uma prática que me foi muito significativa 
e transformadora para a abordagem do tema proposto. Trata-se de uma atividade de formação conduzida pelo ator e encenador François Khan" : oficina "A caminho do Jardim das Cerejeiras", cujas informações seguem abaixo. A linha diretriz desta reflexão é, portanto, traçada pelo movimento que me levou a rever o trabalho de memorização do texto no contexto da fala poética do ator. É exatamente para a clarificação deste processo que se voltam as descrições de procedimentos e de conceitos vivenciados. Um primeiro problema que a reflexão sobre uma prática não pode eludir refere-se à questão do ponto de vista, do falar de um lugar, de uma experiência. Um outro problema é oriundo do precedente: certamente que, por se tratar de um tema contemporâneo no que diz respeito à abordagem da voz e da fala no teatro, alguns autores poderiam muito bem integrar e enriquecer este material com referências. Contudo, dada a intensidade e especificidade da abordagem concentrar-me-ei nas referências de François Khan, considerando um artigo seu publicado em um periódico nacional no ano de 2010 e, principalmente, nas anotações que fiz quando na participação na oficina realizada no ano de 2013 na cidade de Uberlândia. Portanto, no que diz respeito às anotações, assumo a responsabilidade da imprecisão que algumas passagens podem conter, por se tratar do meu ponto de vista sobre a experiência e o registro e leitura das falas do autor em discussão.

\section{A oficina e seus desdobramentos}

Asseguravam-me que o medo à palavra e o discurso pesado decorriam do fato de eu transmitir de forma incorreta as idéias e escandir os versos. Sugeriam que eu marcasse em toda a fala as palavras destacáveis. Mas eu sabia que a questão não estava aí. Era preciso afastar-me temporariamente do papel, acalmar os sentimentos excessivamente agitados e a imaginação, encontrar em mim mesmo aquela harmonia que penetra a tragédia de Púchkin ao seu conjunto e dá ao verso tanta transparência e leveza, e então retomar o papel (Stanislavski, 1989, p.491).

Trata-se da oficina de formação e aperfeiçoamento para atores, "A caminho do Jardim das Cerejeiras", coordenada por François Kahn (TEATROdaCAMARA; França), a partir da correspondência entre Anton Tchekhov e Olga Knipper sobre a escritura e a criação de "O jardim das cerejeiras". A oficina ocorreu no evento IV InterFaces

\footnotetext{
2"François Kahn, nasceu na França em 1949, estudou biologia na universidade de Nantes. Fez parte do grupo Théâtre de l'Expérience (Paris, 1972) até a criação coletiva Le Golem, em 1975. No mesmo período, encontrou Jerzy Grotowski e em seguida participou como guia de vários projetos parateatrais do Teatr Laboratorium, grupo do diretor polonês, em Wroclaw (Polônia), até 1981. Fez parte do Gruppo Internazionale l'Avventura de Volterra (Itália, de 1982 a 1985) e participou da direção e criação de vários ateliês organizados pelo grupo: Viae, Actions dans la ville e L'atelier. De 1986 a 1996 participou como ator e dramaturgo dos espetáculos (em particular a trilogia: Laggiù soffia, Era e In carne e ossa) de Roberto Bacci, diretor do Centro per la Sperimentazione e la Ricerca Teatrale di Pontedera. Em 1991 começou a sua colaboração artística com Humberto Brevilheri. A partir de 1995 criou o projeto TEATROdaCAMERA no qual atua como ator em espetáculos em forma de monólogo, apresentados em espaços não teatrais, para um número reduzido de espectadores, baseados em textos literários: A vista de Delft, segundo Marcel Proust; Ottavia, de Gérard de Nerval; Relatório para uma academia, de Franz Kafka. Em 1998, convidado por Cesare Lievi, diretor do Centro Teatrale Bresciano, criou dois espetáculos: Il sogno e la vita (baseado na obra de
}

E.T.A Hoffmann) e O Marinheiro de Fernando Pessoa. Em 1999 se estabeleceu em Cremona onde prosseguiu com o projeto TEATROdaCAMERA com os espetáculos Moloc/Testemunha: Allen Ginsberg, A Marquesa di O. de Heinrich von Kleist e Viagem a Izu de Kawabata Yasunari. Enquanto autor, ator e diretor, criou em maio de 2009, no âmbito do Festival Fabrica Europa de Florença, o espetáculo Les Dormeurs, segundo Walt Whitman e, em março de 2010, na França, o espetáculo Nuisibles, segundo Jean-Loup Trassard. Em 2011 prosseguiu o projeto TEATROdaCAMERA com a criação do monólogo Musica Lontana baseado no conto Os Mortos de James Joyce. Atualmente vive em Nantes (França). Desde 1986 desenvolve, paralelamente ao trabalho de criação, uma atividade pedagógica ministrando oficinas para jovens atores na Itália, Israel, Rússia e Brasil e colaborando nas atividades didáticas das escolas: Scuola d'Arte Drammatica Paolo Grassi, Milão; Nico Pepe, Udine; C.S.R.T, Pontedera; Accademia dei Filodrammatici, Milão; DAMS - Discipline dell'Arte, della Musica e dello Spettacolo, Universidade de Torino e diversas universidades de teatro brasileiras."(material com pequenas modificações cuja fonte: prospecto do espetáculo Viagem a Izu). 
Internacional - Intercâmbio em Artes Cênicas "Sobre técnicas e poéticas nas Artes do Corpo", realizado no período de 15 a 22 de setembro de 2013, na Universidade Federal de Uberlândia.

$\mathrm{Na}$ ocasião, foram realizados cinco encontros diários de quatro horas cada. No geral, a dinâmica foi construída a partir de três momentos: apresentação de conceitos e princípios do trabalho, seguida de uma breve apresentação do contexto das correspondências (textos utilizados), prática de exercícios do Yoga e dinâmicas de memorização de uma carta da obra utilizada. A maior parte do tempo da oficina foi dedicada ao exercício de memorização propriamente dita, ou seja, ao trabalho de escrever o texto como forma de incorporá-lo. Aqui cabe uma breve descrição do procedimento: trata-se de escrever o texto a ser memorizado, sem falá-lo, sem articulá-lo, respeitando pontuação e forma de escrita. Também, deve-se evitar supressão de palavras e pontuação, e evitar, ainda, abreviações de palavras, frases ou expressões próprias de escritas informais. A escrita aqui se constitui em uma espécie de leitura silenciosa:

A leitura falada já está no corpo das pessoas; a criança quando aprende a ler, fala; a questão da leitura silenciosa é recente na história do homem. [...] a criança aprende (a falar) através da memorização do movimento dos lábios, da língua e da glote. Tem este fato de memorizar junto com a articulação. $O$ fato de separar os dois, tem neste exercício um objetivo bem preciso; esse objetivo é de não exatamente memorizar inicialmente com a articulação porque a nossa tendência é de não só memorizar a articulação como de começar a interpretar, dar uma intenção. Então é pra separar as duas coisas, pra isso (neste exercício) se elimina a articulação. [...] é porque permite um outro tipo de trabalho depois. Então não é uma coisa natural, é um esforço. Mas é um esforço que tem como objetivo possibilitar uma forma de liberdade (Khan, 2013, anotações minhas). ${ }^{3}$

Esta consideração, que foi ao mesmo tempo uma ponderação sobre um princípio do trabalho de memorização, abriu o caminho para uma abordagem que, antes de tudo, enfatizou a aproximação silenciosa do texto para um processo de escuta dos sentidos das palavras. A meu ver, o ato de escrever o texto possibilita a conexão entre o ler, o visualizar e o pensar cada palavra. Ou como o próprio François diz: "podemos receber as ressonâncias do texto em nós mesmos e entender o texto sem pronunciá-lo" (François, 2010, p. 149). Na minha experiência com o trabalho, a aproximação conduzida desta forma permitiu uma leitura meditativa e evitou a fixação de formas e a imposição de significados. Mas essa aproximação não seria possível se não se praticasse, ao longo do trabalho, as posições do yoga para equilibrar a respiração, flexibilizar a musculatura e as articulações do corpo. A questão não é o exercício da escrita - o que talvez pudesse ser explorado para uma outra abordagem -, mas exercitar uma nova maneira de visualizar, de incorporar, de assimilar os sentidos das palavras e, a partir daí, possibilitar o "acontecimento" do texto no ato do falar. Na prática, é como se parássemos o tempo para dedicar toda a atenção, foco, escuta, sentidos para o simples ato de escrever e pensar o texto. É, ainda, um esvaziamento da tensão,

3 Todas as citações de François Khan, datadas do ano de 2013, são fragmentos das anotações referentes ao registro que realizei ao longo da oficina. 
da ansiedade, o difícil exercício de sair do estado de multiatenção e de concentrar-se em uma prática.

O deslocamento que esse processo de memorização por meio da escrita imprime ao modo de aproximação e apropriação do texto é, talvez, a maior força de transformação de um prática que, em geral, é apenas a preparação para o trabalho. Contudo, a prática não é isenta de dificuldade. É fato que a fase do "decorar" o texto normalmente é tratada de uma maneira mecânica e, portanto, se torna uma atividade exaustiva e enfadonha. Essa concepção de uma leitura silenciosa por meio da escrita põe em relação, no meu entender, dois planos do trabalho: o de memorizar o texto e o de adentrar no universo sensível da obra de onde se poder extrair o substrato essencial para a criação. A bem dizer, esta prática não tem somente como efeito a memorização do texto, ela produz uma condição de presença da palavra viva no ator. O que constitui a força desta condição é a dedicação de tempo e atenção ao trabalho de acumular os sentidos, as sensações e os impulsos daí gerados:

Todo o tempo que você passa inicialmente só para memorizar o texto com um sentido, isso é fundamental, pois em todo esse momento acumulam-se várias coisas que estão lá, mas que estão agora imprecisas e que pedem para revelar-se. É bom manter por um certo tempo a pressão, como uma panela de pressão, porque depois a ação tende a sair com mais energia (Khan, 2013, anotações minhas).

Dessa prática de escrita resultam dois estados que caracterizam a fala como possível acontecimento poético: a) o primeiro diz respeito ao alcance de um sentido para as palavras; não se trata de atribuir significado mas, sim, de buscar uma espécie de acepção sensível para o ator na relação com as palavras. Esta palavra se torna, assim, viva, presente, em movimento, e incompleta. b) o segundo estado é justamente o silêncio do texto que a escuta do sentido das palavras proporcionam: é o estado de potência, latente. François considera que a urgência com o trabalho na fase de memorização pode promover a fixação da forma e, consequentemente, a perda da liberdade. Portanto, é necessário o labor de escutar as palavras, buscar sentido no texto, pois "um perigo para o ator no dizer o texto é começar a interpreta-lo; é já ter todas as intenções organizadas. É preciso não deixar-se andar demais no início, porque rapidamente vai fixar as coisas e, portanto, não ter mais liberdade" (Khan, 2013, idem). Pude verificar que o ato de escrever o texto cria silêncio, possibilita a escuta dos sentidos das palavras e, consequentemente, a escuta do eco das palavras em si mesmo, ou seja, perceber como o sentido das palavras que emergem do meu encontro com elas ecoam: há algo de mim, ecoando em mim mesmo. Contudo, conforme afirmou François:

Neste exercício de memorização não tem pior crítico do que você mesmo. Nos colocamos ali como quem ao mesmo tempo que vivencia o exercício atribui um juízo. [...] até um certo ponto em que é preciso relaxar o juiz que fica atrás dizendo: você não sabe o texto; você está fazendo assim, etc." (Khan, 2013, anotações minhas).

Posterior a etapa da escrita do texto, no ponto em que os participantes já conseguiam escrever o texto com fluência, foram propostas a realização de movimen- 
tos corporais, deslocamentos pelo espaço, variações de planos espaciais, e, também, manipulação de objetos como bolas, cadeiras, etc, ao mesmo tempo em que "passo" mentalmente o texto, ou seja, penso e visualizo o material memorizado. Neste ponto, à medida em que a atenção está dividida entre o pensar o texto e o executar as ações e movimentos, duas dificuldades surgiram: a) passar o texto mentalmente com a mesma velocidade necessária para escrita, sem acelerar, sem pular etapas e fragmentos; b) evitar falar o texto, ou seja, pronunciá-lo. É com a "mentalização" do texto que devemos nos ocupar, ao mesmo tempo em que realizamos as atividades proposta: no âmbito da oficina realizamos ações simples, mas constatou-se a possibilidade de intensificar as atividades e de variar os ambientes de modo que a atenção seja ainda mais exigida.

Sobre esta etapa do trabalho proposto, François escreveu:

Em seguida, é preciso dominar estes automatismos e adquirir um tipo de liberdade que passa pela divisão da atenção. No inicio, toda nossa atenção é dirigida somente para a memória do texto. Passa-se o texto numa situação protegida de distrações (por exemplo, numa sala calma e silenciosa) até poder percorrer mentalmente o texto da maneira mais fluida possível, sem erro ou interrupção. A ênfase aqui é: precisão e velocidade. Depois, é preciso dividir a atenção, por exemplo, obrigando-se a fazer uma atividade corporal bem completa (correr, fazer exercícios físicos, nadar...) ou então uma atividade manual que requer precisão (costurar, lavar a louça, cortar lenha etc..) sempre passando mentalmente o texto na cabeça sem perder o rigor, a fluência e sem esquecer, é claro, da atenção (Khan, 2010, p. 150).

Posterior ao trabalho de escrita, de visualização interna das palavras, do pensar o texto, passamos ao exercício de articular a fala no "plano pessoal" ou seja, em baixa intensidade. François afirma ser importante o trabalho com a "voz baixa" (aqui se referindo à intensidade - volume), como forma de perceber o que acontece "dentro" do corpo. Também, como estratégia de o ator não se esconder atrás do "barulho da voz": "escutar o que acontece realmente no corpo e talvez registrar o que possibilitou esse estado, como certa emoção por exemplo" (Khan, 2013, idem).

Neste trabalho acrescentou-se o cuidado com a gestualidade, ou seja, com a movimentação do corpo. É este aspecto que demanda distinguir controle do movimento e bloqueio do mesmo. Dar passagem, fluência, naturalidade ao movimento e gestualidade do corpo no ato de falar e de compor a ação vocal. É preciso que o ator tenha consciência do movimento do corpo - desde o mais sutil -, sem que isso se torne um bloqueio para a fluência do mesmo. Nesta etapa do trabalho, foi comum entre os participantes a situação de tentar dizer o texto sem mexer excessivamente os braços e mãos e, no entanto, os braços se colocaram tensos com movimentos pouco naturais e orgânicos. O mesmo acontecia com as pernas, com os apoios do peso do corpo: quando realizamos a atividade de dizer o texto sentados, era comum entre os participantes apoiarem o peso do corpo nas mãos que estavam apoiadas no chão e, consequentemente, os braços e cintura escapular ficavam tensas e sem fluência para o movimento. François diz que:

Deve-se estar atento para os gestos pois os mesmos poderão assumir uma espécie de substituição de intenção e sentido do texto. Contudo, trata-se de dar liberdade 
para o fluxo natural do movimento onde se pode controlar a gestualidade mas não bloqueá-la (Khan, 2013, anotações minhas).

Do mesmo modo, o movimento do "olhar" precisa de atenção. À medida que começamos o trabalho de dizer o texto passamos a atentar para a necessidade de "acolher" a presença do outro. Ou seja, começamos a direcionar o texto - um "falar com" - para as pessoas que estavam localizadas próximas. Neste sentido, a ideia do "acolher" a presença e o olhar do outro, aponta para um estado em que eu não "digo" ou "mostro" que estou olhando o outro, eu apenas o olho e o vejo diante de mim. A relação do olhar com a fala é demasiada ampla caso se considere a condição necessária para uma comunicação sutil por meio da ação vocal. O simples exercício de dizer o texto para as pessoas que estavam espacialmente próximas revelou, neste ponto, uma dificuldade suplementar que concerne ao processo de composição da presença da fala. É fato, a memorização por meio da escrita permiti alcançar as seguintes condições na relação com o texto: desbloqueio, fluência e liberdade. No que concerne à primeira, é a condição em que o "pensar" e acionar o texto se faz de modo livre sem interrupções, sem barreiras e dificuldades. Consequentemente, a fluência se torna possivel e favorece a criação de sentidos, de emoções e sensações. A liberdade, por sua vez, permite que o ator possa estar completamente entregue à relação com o público. Todas essas condições parecem, então, convergir para um ponto central: o acontecimento poético.

É certo que a possibilidade de o ator estar inteiramente voltado para a relação e o contato com o público, sem que barreiras possam interromper ou tirar a atenção deste encontro, fortalece a experiência que daí poderá surgir. É certo também, que a apropriação plena do texto cria condições favoráveis para uma atuação livre, aberta e intensa. Não há, neste caso, improviso: há acolhimento, atualização e construção de presença; uma presença que se faz junto, conquistada e não imposta.

\section{Considerações finais}

A fé no poder das palavras é uma reminiscência de nossas crenças mais antigas: a natureza está animada; cada objeto possui uma vida própria; as palavras que são os duplos do mundo objetivo, são também animadas. A linguagem, como o universo, é um mundo de chamadas e respostas; fluxo e refluxo, união e separação, inspiração e expiração. Algumas palavras se atraem, outras se repelem, e todas se correspondem (Paz, 1982, p. 62).

Na construção da fala no contexto do trabalho do ator a memorização do texto constitui etapa decisiva que certamente influenciará em toda a criação. A ideia de trabalhar o texto a partir da leitura silenciosa, ou seja, na escrita do texto como forma de memorização do mesmo, permite uma aproximação mais profunda com os sentidos das palavras. $O$ argumento principal é que a memorização sem a fixação de formas modos de dizer - favorece a espontaneidade da fala, bem como uma atuação em que o ator está isento das restrições de barreiras técnicas corporais e vocais e, portanto, autônomo para entregar-se à relação com o público.

Parece-me que se pode convir que essa prática é antes um investimento na 
escuta das palavras, que uma metodologia para se compor a fala. O procedimento de modo algum determina uma forma de "dizer o texto", ao mesmo tempo em que qualifica esse "dizer".

Enquanto o "decorar" o texto repetindo-o em voz alta pode levar-nos a fixação de formas predeterminadas, a escrita institui, antes, um convívio silencioso com a essência e os sentidos das palavras: é reconhecer a força da palavra. Também, a escuta pressupõe tomada de consciência do processo e fluxo dos movimentos do corpo. Tal percepção sutil possibilita que o trabalho se dê de forma fluída, orgânica e integrada, de modo que a composição possa ocorrer com liberdade e autonomia.

Contudo, como nos alerta François, cada texto e contexto de trabalho exigirá flexibilidade e clareza das necessidades apresentadas. O processo de memorização, portanto, poderá ser realizado por meio de diferentes procedimentos em diálogo com as peculiaridades do trabalhos e das pessoas envolvidas:

Emprego um método muito preciso, mas flexível e adaptável a praticamente todas as situações. No entanto, relembro que é meramente um método, não mais que isso e que cada texto, cada situação teatral, cada grupo de teatro e cada ator requer um trabalho de memorização um pouco diferente (Khan, 2010, p. 148-149).

\section{Referências}

ALEIXO, Fernando. A voz (do) corpo: memória e sensibilidade. In: Urdimento - Revista de Estudos em Artes Cênicas, número 06, 2004. Disponível em: http://www.ceart. udesc.br/ppgt/urdimento/2004/urdimento_6-148-163.pdf). Acesso em: abr. 2014.

GROTOWSKI, Jerzy. O que foi. In: O Teatro Laboratório de Jerzy Grotowski 19591969 / textos e materiais de Jerzy Grotowski e Ludwik Flaszen com um escrito de Eugênio Barba; curadoria de Ludwik Flaszen e Carla Pollastrelli com a colaboração de Renata Molinari; tradução para o português Berenice Raulino. São Paulo: Perspectiva: SESC; Pontedera, IT: Fondazione Pontedera Teatro, 2007, p. 199 - 211.

PAZ, Octavio. O Arco e a Lira. Rio de Janeiro: Nova Fronteira, 1982.

KHAN, François. Reflexões sobre a prática da memória no ofício do ator de teatro. In: Sala Preta - Revista de Artes Cênicas, volume 9, 2010. Disponível em: http://www. revistas.usp.br/salapreta/article/view/57398/60380. Acesso em: jan. de 2014.

STANISLAVSKI, Constantin. Minha vida na arte. Rio de Janeiro: Civilização Brasileira, 1989.

Recebido em: 17/09/2014

Aprovado em: 20/09/2014 